\title{
PENGARUH KOMUNIKASI INTERNAL DAN DISIPLIN KERJA TERHADAP KINERJA PEGAWAI
}

\author{
Mirna Sari ${ }^{1)}$, Herman Sjaharuddin ${ }^{2)}$, Nurlaely Razak ${ }^{3)}$ \\ mirnasari12ips1@gmail.com \\ ${ }^{1)}$ Mahasiswa Program Studi Manajemen pada Sekolah Tinggi Ilmu Ekonomi Bongaya \\ Makassar \\ 2, 3) Dosen Program Studi Manajemen pada Sekolah Tinggi IImu Ekonomi Bongaya \\ Makassar
}

\begin{abstract}
ABSTRAK
Penelitian ini bertujuan untuk mengetahui pengaruh Komunikasi Internal dan Disiplin Kerja Terhadap Kinerja Pegawai Pada Kantor Walikota Makassar (Studi Kasus Pada Bagian Kesejatraan Rakyat). Pengumpulan data menggunakan data primer yang diperoleh dari hasil wawancara dengan pihak manajemen atau para pegawai pada Kantor Walikota Makassar (Studi Kasus Pada Bagian Kesejatraan Rakyat) yang berhubungan dengan manajemen sumber daya manusia sedangkan data sekunder adalah data-data yang bersumber dari data yang terkait manajemen sumberdaya manusia serta studi pustaka dan literatur-literatur yang bersangkutan. Berdasarkan hasil analisa data dan pembahasan hasil penelitian yang telah dijelaskan, maka dapat diambil kesimpulan bahwa Komunikasi Internal dan Disiplin Kerja memiliki pengaruh yang positif yang siknifikan terhadap kinerja pegawai baik secara simulatan maupun secara persial.
\end{abstract}

Kata kunci: Komunikasi Internal, Disiplin Kerja dan Kinerja Pegawai.

\begin{abstract}
This study aims to determine the effect of Internal Communication and Work Discipline on Employee Performance At the Office of Makassar Mayor (Case Study On The People's Welfare Section). Data collection using primary data obtained from interviews with the management or employees at the Mayor's Office Makassar (Case Study On the People's Welfare Section) associated with human resource management while secondary data is data that comes from data related to the management of resources human and literature study and the relevant literature. Based on the results of data analysis and discussion of the results of research that has been described, it can be concluded that Internal Communication and Work Discipline has a significant positive impact on employee performance either simulatan or persial.
\end{abstract}

Keywords: $\quad$ Internal Communication, Work Discipline and Employee Performance.

\section{A. Latar Belakang}

Undang-Undang No. 5 Tahun 2014 tentang Aparatur Sipil Negara, dijelaskan bahwa pegawai negeri yang kemudian disebut dengan Aparatur Sipil Negara adalah setiap warga negara Indonesia yang telah memenuhi syarat yang ditentukan, diangkat oleh pejabat yang berwenang dan diserahi tugas dalam suatu jabatan negeri, atau diserahi tugas negara lainnya, dan digaji berdasarkan peraturan perundang-undangan yang berlaku. 


\section{JURNAL ORGANISASI DAN MANAJEMEN}

Issue 1 (October, 2017)

Pemerintah Kota Makassar dalam hal ini, Kantor Walikota Makassar terkhusus merupakan organisasi yang didalamnya terdiri dari sekumpulan satuan kerja perangkat daerah yang kesemuanya dituntut untuk melaksanakan tugas dengan disiplin kerja yang baik demi mengembangkan serta memajukan kualitas pegawai dan masyarakat Kota Makassar. Salah Satu Satuan Kerja Perangkat Daerah (SKPD) yang terdapat pada Kantor Pemerintahan Kota Makassar adalah Kesejahteraan Rakyat, yang memiliki peran strategis dalam menyusun dan melaksanakan kebijakan terhadap fasilitas dan pemberdayaan pegawai. Dalam melaksanakan perannya tersebut, pegawai yang memiliki kemampuan dan keahlian dibidangnya menjadi variabel utama dalam melaksanakan tugas dan fungsi pada SKPD Kesejahteraan Rakyat. Untuk dapat melaksanakan tugastugas tersebut

, Aparatur Sipil Negara di tuntut untuk menampilkan sikap kerja yang baik dan untuk memunculkan sikap kerja tersebut harus dibangun melalui komunikasi yang sehat. Sebagai cerminan komunikasi yang sehat, Komunikasi internal diperlukan untuk memelihara hubungan antara pegawai atau hubungan antara pegawai dengan pimpinan.

Berdasarkan teorinya, kinerja individu dijelaskan melalui tiga faktor, yaitu kemampuan individu melakukan pekerjaan tersebut, tingkat usaha yang dicurahkan dan dukungan organisasi yang secara luas dalam literature manajemen diformulasikan sebagai : Kinerja (Performance $/ \mathrm{P})=$ Kemampuan (Ability / A) x Usaha (Effort / E) x Dukungan (Support / S) (Robbins, 1996, dalam dalam Amin, dkk., 2016). Teori tersebut yang mendasari terjadinya hubungan antar variabel dalam penelitian ini yaitu, pengaruh komunikasi internal terhadap kinerja, dan disiplin kerja terhadap kinerja. Kemampuan (ability) merupakan representasi dari kemampuan pegawai untuk berkomunikasi secara internal, usaha (effort) dan dukungan (support) merupakan kemampuan pegawai untuk melaksanakan disiplin kerja, dapat dijelaskan jika kemampuan (berkomunikasi secara internal) dan usaha serta dukungan (disiplin kerja) saling berinteraksi maka kinerja pegawai yang tinggi dapat diciptakan. Berdasarkan teori tersebut, maka penciptaan kinerja pegawai yang tinggi dipengaruhi oleh komunikasi internal dan disiplin kerja.

\section{B. Tinjauan Pustaka}

\section{Komunikasi Internal}

Secara etimologis komunikasi berasal dari bahasa Latin, yaitu cum, kata depan yang artinya dengan atau bersama dengan, dan kata units, kata bilangan yang berarti satu. Dua kata tersebut membentuk kata benda communio, yang dalam bahasa inggris disebut dengan communion, yang berarti kebersamaan, persatuan, persekutuan, gabungan, pergaulan, atau hubungan. Karena untuk melakukan communion, diperlukan usaha dan kerja. Kata communio dibuat kata kerja communicate, yang berarti membagi sesuatu dengan seseorang, tukar menukar, membicarakan sesuatu dengan orang, membicarakan sesuatu dengan orang, memberitahukan sesuatu kepada seseorang, bercakap-cakap, bertukar pikiran, berhubungan, berteman (Nurjaman dan Umam, 2012:35).

\section{Disiplin Kerja}

Disiplin kerja adalah kemampuan kerja seseorang untuk secara teratur, tekun, terus-menerus, dan bekerja sesuai dengan aturan-aturan yang berlaku dengan tidak melanggar aturan-aturan yang sudah ditetapkan (Hasibuan dalam Barnawi 2012:112). Disiplin kerja adalah suatu alat yang digunakan para manajer untuk berkomunikasi dengan karyawan agar mereka bersedia untuk mengubah suatu perilaku dan untuk meningkatkan kesadaran juga kesediaan seseorang 


\section{JURNAL ORGANISASI DAN MANAJEMEN}

Issue 1 (October, 2017)

agar menaati semua peraturan dan norma sosial yang berlaku di suatu perusahaan (Rivai \& Sagala, 2013:825).

\section{Kinerja Pegawai}

Kinerja merupakan tingkat keberhasilan seseorang secara keseluruhan selama periode tertentu di dalam melaksanakan tugas dibandingkan dengan berbagai kemungkinan hasil kerja, target, atau sasaran atau kriteria yang telah ditentukan terlebih dahulu dan telah disepakati bersama. Artinya bahwa hasil kerja seseorang merupakan evaluasi yang telah dilakukan berdasarkan periode tertentu yang akan dibandingkan dengan sasaran atau target tujuan perusahaan. Apabila kinerja seseorang tersebut diatas target yang telah disepakati, maka dapat dikatakan kinerja individu seseorang tersebut baik dan sesuai yang diharapkan. Begitu pula sebaliknya (Iryani, 2009)

\section{Metode Penelitian}

Penelitian ini termasuk penelitian metode deskriptif kuantitatif yang bertujuan untuk menjelaskan suatu fenomena empiris yang disertai data statistic dan pola hubungan antara variabel. Penelitian ini menggunakan analisis SEM (Structural equation modeling) dibantu dengan WaphPLS Ver. 5.0 sebagai peralatan penelitian.

\section{Hasil Penelitian}

\section{Evaluasi Model Pengukuran (Outer Model) Model 1}

Pada model 1 yaitu evaluasi outer model dilakukan melalui 2 kriteria yaitu convergent validity, dan composite reliability. Berikut ini adalah hasil pengolahan data:

a. Convergent Validity (Validitas Konvergen)

Evaluasi outer model dilakukan melalui 3 kriteria yaitu convergent validity, discriminant validity dan composite reliability. Convergent validity dari model pengukuran dapat dilihat dari korelasi antara skor indikator dengan skor konstruknya (loading factor) dengan kriteria nilai loadingfactor dari setiap indikator lebih besar dari 0,70 dapat dikatakan valid. Selanjutnyauntuk nilai pvalue apabila $<0,05$ dianggap signifikan. Loading factor antara 0,40-0,70 harus tetap dipertimbangkan untuk dipertahankan. Selanjutnya dijelaskan pula bahwa, indikator dengan loading $<0,40$ dihapus dari model. Penghapusan indikator dengan loading antara 0,40-0,70 dilakukan apabila indikator tersebut dapat meningkatkan AVE dan composite reliability diatas nilai batasannya. Nilai batasan untuk AVE 0,50 dan composite reliability adalah 0,50 (Machfud dan Dwi, 2013: 66; dalam Ovi Arista, 2015). Hasil pengolahan Convergent Validity dapat dilihat pada tabel berikut ini:

Tabel 1. Hasil Output Combined Loading and Cross-Loading (model1)

\begin{tabular}{|c|c|c|c|c|c|c|}
\hline MODEL 1 & KI & DK & KRJ & SE & P value & KETERANGAN \\
\hline X11 & $(0,746)$ & $-0,087$ & $-0,356$ & 0,113 & $<0,001$ & Valid \\
\hline X12 & $(0,766)$ & $-0,567$ & 0,568 & 0,112 & $<0,001$ & Valid \\
\hline X13 & $(0,493)$ & $-0,172$ & 0,18 & 0,125 & $<0,001$ & Tdk. Valid \\
\hline X14 & $(0,447)$ & 0,083 & $-0,342$ & 0,128 & $<0,001$ & Tdk. Valid \\
\hline X15 & $(0,617)$ & 0,887 & $-0,171$ & 0,119 & $<0,001$ & Valid \\
\hline X21 & 0,242 & $(0,521)$ & $-0,336$ & 0,124 & $<0,001$ & Tdk. Valid \\
\hline X22 & $-0,063$ & $(0,961)$ & $-0,131$ & 0,103 & $<0,001$ & Valid \\
\hline X23 & $-0,073$ & $(0,931)$ & $-0,095$ & 0,104 & $<0,001$ & Valid \\
\hline
\end{tabular}




\section{JURNAL ORGANISASI DAN MANAJEMEN}

Issue 1 (October, 2017)

Lanjutan Tabel 1. Hasil Output Combined Loading and Cross-Loading (model1)

\begin{tabular}{|c|c|c|c|c|c|c|}
\hline MODEL 1 & KI & DK & KRJ & SE & P value & KETERANGAN \\
\hline X24 & $-0,092$ & $(' 0,595)$ & 0,915 & 0,12 & $<0,001$ & Tdk. Valid \\
\hline X25 & 0,063 & $(0,912)$ & $-0,171$ & 0,105 & $<0,001$ & Valid \\
\hline Y11 & 0,112 & 0,035 & $(0,887)$ & 0,106 & $<0,001$ & Valid \\
\hline Y12 & $-0,049$ & 0,004 & $(0,35)$ & 0,133 & 0,006 & Tdk. Valid \\
\hline Y13 & $-0,026$ & $-0,105$ & $(0,906)$ & 0,106 & $<0,001$ & Valid \\
\hline Y14 & $-0,063$ & 0,067 & $(0,935)$ & 0,104 & $<0,001$ & Valid \\
\hline
\end{tabular}

Sumber : Data Primer (diolah WarpPLS 5.0, 2017)

Berdasarkan hasil pengolahan data diatas maka dapat dijelaskan bahwa Convergent validity (uji validitas) untuk konstruk Komunikasi Internal (X1). Pada model 1 diatas, hasil pengolahan data tersebut menjelaskan bahwa dari 5 indikator komunikasi internal, yaitu X11, X12, X13, X14, dan X15 ada 2 indikator tersebut yang tidak memenuhi standar Convergent Validity dengan nilai $>0.70$ dan P-value juga telah memenuhi syarat yaitu memiliki nilai sebesar $<0,001$ ( $<$ $0,05)$ dimana indikator $\mathrm{X} 13$, dan $\mathrm{X} 14$, tidak memenuhi standar Convergent Validity sehingga indikator $\mathrm{X} 13$, dan indikator $\mathrm{X} 14$, tersebut harus dikeluarkan pada model 2.

Convergent validity (uji validitas) untuk konstruk Disiplin Kerja (X2). Hasil pengolahan data pada model 1 diatas menjelaskan bahwa terdapat 2 indikator yang tidak memenuhi standar Convergent validity yaitu, X21 dan X24<0.70, sehingga indikator tersebut harus dikeluarkan dari model 2.

Convergent validity (uji validitas) untuk konstruk kinerja pegawai (Y). Pada model 1 diatas, hasil pengolahan data tersebut menjelaskan bahwa dari 4 indikator komunikasi internal, yaitu Y11, Y12, Y13, dan $\mathrm{Y} 14$, ada 1 indikator tersebut yang tidak memenuhi standar Convergent Validity dengan nilai $>0.70$ dan P-value juga tidak memenuhi syarat yaitu memiliki nilai sebesar $<0,001$ ( $<$ $0,05)$ dimana indikator Y12, tidak memenuhi standar Convergent Validity sehingga indikator Y12 tersebut harus dikeluarkan pada model 2.

Pengukuran lainnya dari convergent validity adalah dengan melihat nilai AVE (Average Variance Extracted). Menurut pendapat (Mahfud Sholihin dan Dwi Ratmono (2013: 73), dalam Arista, 2015) menyatakan bahwa AVE (Average Variance Extracted) juga digunakan untuk evaluasi validitas konvergen, kriteria yang harus dipenuhi yaitu nilai AVE $>0,50$.

b. Uji Composite Reliability

Suatu variabel yang dipandang mampu (handal) dalam menjelaskan data dari variabel tersebut, pengujiannya dapat dilihat pada nilai composite reliability dan Cronbach's Alpha $<0,60$, untuk itu dapat diperlihatkan pada tabel berikut:

Table 2 Latent variable coefficients (composite reliability) (model 1)

\begin{tabular}{|c|c|c|c|}
\hline MODEL 1 & KI & DK & KRJ \\
\hline R-Squared & & & 0,448 \\
\hline Composite reliab. & 0,757 & 0,989 & 0,872 \\
\hline Cronbach's Alpha & 0,600 & 0,848 & 0,789 \\
\hline Avg. Var. Extrac. & 0,394 & 0,650 & 0,651 \\
\hline Full Collin. VIF & 1,403 & 1,714 & 1.723 \\
\hline Q-Squared & & & 0.453 \\
\hline
\end{tabular}

Sumber : Data Primer (diolah WarpPLS Ver 5.0, 2017) 


\section{JURNAL ORGANISASI DAN MANAJEMEN}

Issue 1 (October, 2017)

Nilai composite reliability untuk variabel komunikasi internal sebesar $0,757>0,60$ sedangkan untuk variabel disiplin kerja sebesar 0,989 $>0,60$ dan yang terakhir pada variabel kinerja pegawai sebesar 0,872 $>0,60$. Selanjutnya untuk Cronbach's Alpha pada variabel komunikasi internal sebesar 0,600>0,60 sedangkan untuk variabel disiplin kerja sebesar 0,848 >0,60 dan yang terakhir pada variabel kinerja pegawai sebesar 0,789>0,60. Untuk nilai Average Variances Extracted (AVE)/ nilai variasi rata-rata pada variabel komunikasi internal sebesar 0,394 >0,50 sedangkan untuk variabel disiplin kerja sebesar $0,650<0,50$ dan yang terakhir pada variabel kinerja pegawai sebesar 0,651> 0,50 .

Berdasarkan hasil tersebut maka nilai yang belum memenuhi kriteria pengujian ditemukan pada nilai variasi rata-rata (AVE) untuk variabel pemanfaatan teknologi informasi, sehingga terdapat cukup alasan yang kuat untuk mengujinya kembali pada model 2.

\section{Evaluasi Model Pengukuran (Outer Model) Model 2}

Pada model 2 yaitu evaluasi outer model dilakukan melalui 3 kriteria yaitu convergent validity, discriminant validity dan composite reliability. Berikut ini adalah hasil pengolahan data:

a. Convergent Validity (Validitas Konvergen)

Convergent validity dari model pengukuran dapat dilihat dari korelasi antaraskor indikator dengan skor konstruknya (loading factor) dengan kriteria nilailoading factor dari setiap indikator lebih besar dari 0,70 dapat dikatakan valid.Selanjutnya untuk nilai $p$-value apabila $<0,05$ dianggap signifikan Hasil pengolahan Convergent Validity dapat dilihat pada tabel berikut ini:

Table 3 Hasil output combined loadings and cross-loading

\begin{tabular}{|c|c|c|c|c|c|c|}
\hline MODEL 2 & KI & DK & KRJ & SE & P value & KETERANGAN \\
\hline X11 & $(0,848)$ & $-0,121$ & $-0,423$ & 0,108 & $<0,001$ & Valid \\
\hline X12 & $(0,777)$ & $-0,561$ & 0,536 & 0,111 & $<0,001$ & Valid \\
\hline X15 & $(0,649)$ & 0,829 & $-0,088$ & 0,118 & $<0,001$ & Valid \\
\hline X22 & $-0,001$ & $(0,979)$ & $-0,023$ & 0,102 & $<0,001$ & Valid \\
\hline X23 & $-0,04$ & $(0,949)$ & 0,013 & 0,104 & $<0,001$ & Valid \\
\hline X25 & 0,041 & $(0,937)$ & 0,01 & 0,104 & $<0,001$ & Valid \\
\hline Y11 & 0,093 & 0,032 & $(0,902)$ & 0,106 & $<0,001$ & Valid \\
\hline Y13 & $-0,026$ & $-0,095$ & $(0,911)$ & 0,105 & $<0,001$ & Valid \\
\hline Y14 & $-0,064$ & 0,062 & $(0,939)$ & 0,104 & $<0,001$ & Valid \\
\hline
\end{tabular}

Sumber : Data Primer (diolah WarpPLS Ver 5.0, 2017)

Hasil pada tabel diatas, menunjukkan hasil pengujian Convergent validity untuk model 2, dimana pada model 1 sebelumnya terdapat beberapa indikator pada variabel komunikasi internal, disiplin kerja dan kinerja pegawai yang tidak memenuhi standar Convergent validity sehingga dilakukan pengujian model 2 . Pada pengujian model 2 diatas, semua indikator yang tidak memenuhi standar Convergent validity telah dikeluarkan dari model, sehingga pengujian Convergent validity pada model 2 telah memenuhi standar Convergent Validity dengan nilai $>0.70$ dan $P$-value juga telah memenuhi syarat yaitu memiliki nilai sebesar $<0,001(<0,05)$ untuk seluruh indikator dari variabel komunikasi internal, disiplin kerja dan kinerja pegawai. 


\section{JURNAL ORGANISASI DAN MANAJEMEN}

Issue 1 (October, 2017)

b. Uji Composite Reliability

Suatu variabel yang dipandang mampu (handal) dalam menjelaskan data dari variabel tersebut, pengujiannya dapat dilihat pada nilai composite reliability dan Cronbach's Alpha $<0,60$, untuk itu dapat diperlihatkan pada tabel berikut:

Table 4 Latent variable coefficients (composite reliability) (model 1)

\begin{tabular}{|c|c|c|c|}
\hline MODEL 2 & KI & DK & KRJ \\
\hline R-Squared & & & 0,412 \\
\hline Composite reliab. & 0,805 & 0,969 & 0,941 \\
\hline Cronbach's Alpha & 0,634 & 0,952 & 0,906 \\
\hline Avg. Var. Extrac. & 0,582 & 0,912 & 0,842 \\
\hline Full Collin. VIF & 1,414 & 1,468 & 1,505 \\
\hline Q-Squared & \multicolumn{3}{|l}{} \\
\hline
\end{tabular}

Sumber : Data Primer (diolah WarpPLS Ver 5.0, 2017)

Nilai composite reliability untuk variabel komunikasi internal sebesar $0,805>0,60$ sedangkan untuk variabel disiplin kerja sebesar 0,969 > 0,60 dan yang terakhir pada variabel kinerja pegawai sebesar $0,941>0,60$. Selanjutnya untuk Cronbach's Alpha pada variabel komunikasi internal sebesar 0,634 >0,60 sedangkan untuk variabel disiplin kerja sebesar 0,952 > 0,60 dan yang terakhir pada variabel kinerja pegawai sebesar 0,906>0,60. Untuk nilai Average Variances Extracted (AVE)/ nilai variasi rata-rata pada variabel komunikasi internal sebesar 0,582 >0,50 sedangkan untuk variabel disiplin kerja sebesar $0,912<0,50$ dan yang terakhir pada variabel kinerja pegawai sebesar 0,842 > 0,50 .

Berdasarkan hasil tersebut maka keseluruhan nilai memenuhi kriteria pengujian, sehingga terdapat cukup alasan yang kuat untuk mengujinya kembali pada model 2. memiliki alasan yang kuat untuk dianalisis lebih lanjut dimodel 2.

Tabel 5 Nilai AVE (Average Variance Extracted)

\begin{tabular}{|c|c|l|l|}
\hline \multicolumn{4}{|c|}{ Average Variance Extracted (AVE) } \\
\hline Variabel Laten & Nilai AVE & Kriteria & Keterangan \\
\hline KI & 0,582 & $>0,50$ & Memenuhi convergent validity \\
\hline DK & 0,912 & $>0,50$ & Memenuhi convergent validity \\
\hline KRJ & 0,842 & $>0,50$ & Memenuhi convergent validity \\
\hline
\end{tabular}

Sumber : Data Primer (diolah WarpPLS Ver 5.0, 2017)

Berdasarkan hasil tersebut ketiga konstruk telah memenuhi convergent validity. Komunikasi internal dengan nilai $0,582>0,50$, disiplin kerja dengan nilai 0,912 juga telah memenuhi nilai $>0,50$ dan Kinerja pegawai memiliki nilai 0,842 $>0,50$. Kesimpulannya keseluruhan variabel telah memenuhi kriteria convergent validity.

\section{c. Dicriminant Validity}

Discriminant validity dinilai dari cross loading pengukuran dengan konstruk. Dapat dilihat dengan melihat loading konstruk laten, yang akan memprediksi indikatornya lebih baik daripada konstruk lainnya. Jika korelasi konstruk dengan pokok pengukuran (setiap indikator) lebih besar daripada ukuran konstruk lainnya maka validitas diskriminan terpenuhi. 


\section{JURNAL ORGANISASI DAN MANAJEMEN}

Issue 1 (October, 2017)

Tabel 6 Nilai loading konstruk laten indikator ke konstruk lainnya

\begin{tabular}{|c|c|c|c|c|c|c|}
\hline \multirow{2}{*}{ Indikator } & \multirow{2}{*}{ Loading } & & \multicolumn{3}{|c|}{$\begin{array}{c}\text { Nilai Loading ke konstruk } \\
\text { lainnya }\end{array}$} & Keterangan \\
\cline { 4 - 6 } & & $\mathbf{K I}$ & $\mathbf{D K}$ & $\mathbf{K R J}$ & \\
\hline $\mathbf{X}_{\mathbf{1 1}}$ & $(0,848)$ & $>$ & & $-0,121$ & $-0,423$ & Terpenuhi \\
\hline $\mathbf{X}_{\mathbf{1 2}}$ & $(0,777)$ & $>$ & & $-0,561$ & 0,536 & Terpenuhi \\
\hline $\mathbf{X}_{\mathbf{1 5}}$ & $(0,649)$ & $>$ & & 0,829 & $-0,088$ & Terpenuhi \\
\hline $\mathbf{X}_{\mathbf{2 2}}$ & $(0,979)$ & $>$ & $-0,001$ & & $-0,023$ & Terpenuhi \\
\hline $\mathbf{X}_{\mathbf{2 3}}$ & $(0,949)$ & $>$ & $-0,04$ & & 0,013 & Terpenuhi \\
\hline $\mathbf{X}_{\mathbf{2 5}}$ & $(0,937)$ & $>$ & 0,041 & & 0,01 & Terpenuhi \\
\hline $\mathbf{Y}_{1 \mathbf{1 1}}$ & $(0,902)$ & $>$ & 0,093 & 0,032 & & Terpenuhi \\
\hline $\mathbf{Y}_{13}$ & $(0,911)$ & $>$ & $-0,026$ & $-0,095$ & & Terpenuhi \\
\hline $\mathbf{Y}_{\mathbf{1 4}}$ & $(0,939)$ & $>$ & $-0,064$ & 0,062 & & Terpenuhi \\
\hline
\end{tabular}

Sumber : Data Primer (diolah WarpPLS Ver 5.0, 2017)

Berdasarkan data di atas, keseluruhan indikator telah memenuhi kriteria validitas diskriminan. Variabel komunikasi internal yang memiliki 3 indikator yang dilambangkan dengan $\mathrm{X} 11, \mathrm{X} 12$, dan $\mathrm{X} 15$. Untuk indikator $\mathrm{X} 11$ memiliki nilai loading 0,848 yang nilai loading-nya lebih besar dari loading ke konstruk lain yaitu $-0,121$ dan $-0,423$ dan ke 2 indikator komunikasi internal lainnya juga memiliki nilai loading yang lebih besar dari nilai loading ke konstruk lain.

Variabel disiplin kerja informasi yang memiliki 3 indikator yang dilambangkan dengan X22, X23 dan X25. Untuk indikator X22 memiliki nilai loading 0,979 yang nilai loading-nya lebih besar dari loading ke konstruk lain yaitu $-0,001$ dan $-0,023$ dan ke 2 indikator disiplin kerja lainnya juga memiliki nilai loading yang lebih besar dari nilai loading ke konstruk lainnya.

Variabel kinerja pegawai memiliki 3 indikator yang dilambangkan dengan Y11, Y13 dan Y14. Untuk indikator Y11 memiliki nilai loading 0,902 yang nilai loading-nya lebih besar dari loading ke konstruk lain yaitu 0,093 dan 0,032 dan ke 2 indikator kinerja pegawai lainnya juga memiliki nilai loading yang lebih besar dari nilai loading ke konstruk lain. Berdasarkan uraian tersebut, dapat disimpulkan bahwa keseluruhan indikator telah memenuhi kriteria validitas diskriminan.

\section{Evaluasi Model Struktural (Inner Model)}

Tahap selanjutnya adalah melakukan evaluasi struktural (inner model) yang meliputi uji kecocokan model (model fit), path coefficient, dan R2. Pada uji kecocokan model terdapat 3 indeks pengujian, yaitu average path coefficient (APC), average Rsquared (ARS) dan average varians factor (AVIF) dengan kriteria APC dan ARS diterima dengan syarat $p-$ value $<0,05$ dan AVIF $<5$ (Mahfud Sholihin dan Dwi Ratmono, 2013: 61). Berikut ini adalah hasil output model fit indices yang disajikan dalam bentuk tabel yaitu:

Table 7 Hasil output model fit indices

\begin{tabular}{|c|c|c|c|c|}
\hline & Indeks & $\boldsymbol{P}$-Value & Kriteria & Keterangan \\
\hline APC & 0,384 & $\mathrm{P}<0,001$ & $\mathrm{P}<0,05$ & Diterima \\
\hline ARS & 0,412 & $\mathrm{P}<0,001$ & $\mathrm{P}<0,05$ & Diterima \\
\hline AVIF & 1,185 Acceptable if $<5$ & & $\mathrm{AVIF}<5$ & Diterima \\
\hline
\end{tabular}

Sumber : Data Primer (diolah WarpPLS Ver 5.0, 2017) 


\section{JURNAL ORGANISASI DAN MANAJEMEN}

Issue 1 (October, 2017)

Hasil output di atas, menjelaskan bahwa APC memiliki indeks sebesar 0,384 dengan nilai $p-$ value $<0,001$. Sedangkan ARS memiliki indeks sebesar 0,412 dengan $p-$ value $<0,001$. Berdasarkan kriteria, APC sudah memenuhi kriteria karena memiliki nilai $p<0,001$. Begitu pula dengan nilai $p$ dari ARS yaitu $p<0,001$. Nilai AVIF yang harus $<5$ sudah terpenuhi karena berdasarkan data tersebut AVIF nilainya 1,185. Dengan demikian, maka inner model dapat diterima.

\section{a. Hasil Uji Hipotesis}

Hasil korelasi antar konstruk diukur dengan melihat path coefficients dan tingkat signifikansinya yang kemudian dibandingkan dengan hipotesis penelitian yang terdapat di bab dua. Tingkat signifikansi yang dipakai dalam penelitian ini adalah sebesar 5\%. Berikut ini hipotesis yang dimaksudkan untuk membuktikan kebenaran dugaan penelitian yang terdiri dari tiga hipotesis, yaitu:

$\mathrm{H} 1=$ Komunikasi Internal berpengaruh positif dan signifikan terhadap Kinerja Pegawai pada SKPD Kesejahteraan Rakyat Kantor Pemerintahan Kota Makassar.

$\mathrm{H} 2$ = Disiplin Kerja berpengaruh positif dan signifikan terhadap Kinerja Pegawai pada SKPD Kesejahteraan Rakyat Kantor Pemerintahan Kota Makassar.

$\mathrm{H} 3=$ Komunikasi Internal merupakan variabel yang dominan berpengaruh positif dan signifikan terhadap Kinerja Pegawai pada SKPD Kesejahteraan Rakyat Kantor Pemerintahan Kota Makassar.

Berikut ini tabel hasil penelitian dari effect size yang telah diperoleh berdasarkan pengolahan data:

Gambar 1 Full Model

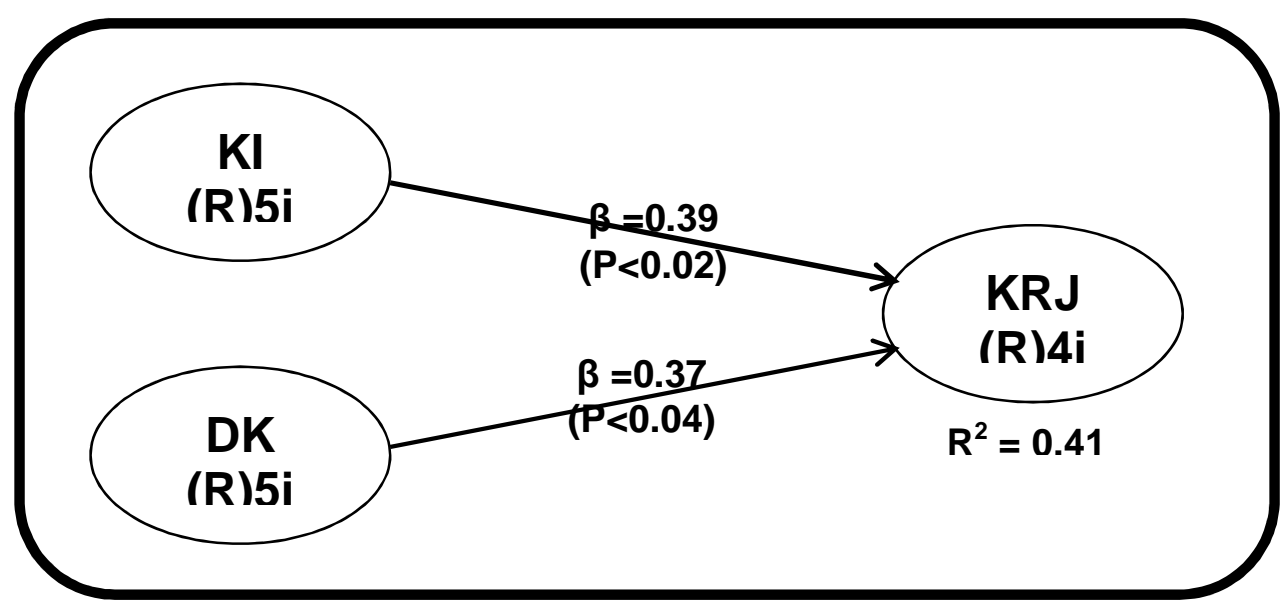

Sumber: Data primer (diolah WarphPLS Ver 5.0, 2017)

Berikut ini tabel hasil pengujian hipotesis yang telah diperoleh berdasarkan pengolahan data:

Table 8. Pengujian hipotesis

\begin{tabular}{|c|c|c|c|c|}
\hline Kriteria & Variabel & KI & DK & KRJ \\
\hline \multirow{3}{*}{ Path coefficients } & KI & - & - & - \\
\cline { 2 - 5 } & DK & - & - & - \\
\cline { 2 - 5 } & KRJ & 0,395 & 0,373 & - \\
\hline \multirow{3}{*}{$p$-values } & KI & - & - & - \\
\cline { 2 - 5 } & DK & - & - & - \\
\cline { 2 - 5 } & KRJ & $<0,002$ & 0,004 & - \\
\hline
\end{tabular}




\section{JURNAL ORGANISASI DAN MANAJEMEN}

Issue 1 (October, 2017)

Lanjutan Table 8. Pengujian hipotesis

\begin{tabular}{|c|c|c|c|c|}
\hline Kriteria & Variabel & KI & DK & KRJ \\
\hline \multirow{3}{*}{ Effect size for path } & KI & - & - & - \\
\cline { 2 - 5 } & DK & - & - & - \\
\cline { 2 - 5 } & KRJ & 0,215 & 0,198 & - \\
\hline
\end{tabular}

Sumber: Data primer (diolah WarphPLS Ver 5.0, 2017)

Hasil output di atas, menjelaskan bahwa path coefficients untuk variabel komunikasi internal terhadap kinerja pegawai memiliki indeks sebesar 0,395 dengan nilai $p$ - value $<0,002$ dan nilai effect size for path 0,215 sedangkan untuk path coefficients variabel disiplin kerja terhadap kinerja pegawai memiliki indeks sebesar 0,373 dengan $p$ - value 0,004 nilai effect size for path 0,198. Berikut ini merupakan gambar hasil penelitian dari effect size yang telah diperoleh berdasarkan pengolahan data

Setelah melakukan uji hipotesis, berikut ini tabel yang merangkum uji hipotesis-hipotesis tersebut :

Table 9 Hasil uji hipotesis

\begin{tabular}{|c|l|c|c|c|}
\hline Hipotesis & Independen & Dependen & $\boldsymbol{p}$-values & Keputusan \\
\hline $\mathrm{H}_{1}$ & $\begin{array}{l}\text { Komunikasi } \\
\text { Internal }\end{array}$ & Kinerja Pegawai & $<0,002$ & Diterima \\
\hline $\mathrm{H}_{2}$ & Disiplin Kerja & Kinerja Pegawai & $<0,004$ & Diterima \\
\hline $\mathrm{H}_{3}$ & $\begin{array}{l}\text { Komunikasi } \\
\text { internal dan } \\
\text { Disiplin kerja }\end{array}$ & Kinerja Pegawai & $\begin{array}{l}\text { Nilai 0,395 } \\
>\text { dari nilai } \\
0,373\end{array}$ & Diterima \\
\hline
\end{tabular}

Sumber: Data primer (diolah WarphPLS Ver 5.0, 2017)

Berdasarkan tabel hasil uji hipotesis di atas, dapat diperoleh:

1) Uji hipotesis 1 diterima, artinya variabel komunikasi internal memiliki pengaruh positif dan signifikan terhadap kinerja pegawai pada SKPD Kesejahteraan Rakyat Kantor Pemerintahan Kota Makassar. Hal ini ditunjukkan dengan nilai beta $(\beta)$ sebesar 0,395 dengan nilai $p$-value $<0.002$.

2) Uji hipotesis 2 diterima, artinya variabel disiplin kerja memiliki pengaruh positif dan signifikan terhadap kinerja pegawai pada SKPD Kesejahteraan Rakyat Kantor Pemerintahan Kota Makassar. Hal ini ditunjukkan dengan nilai beta $(\beta)$ sebesar 0,373 dengan nilai $p$-value $<0,04$.

3) Uji hipotesis 3 diterima, artinya variabel komunikasi internal dominan memiliki pengaruh positif dan signifikan terhadap kinerja pegawai pada SKPD Kesejahteraan Rakyat Kantor Pemerintahan Kota Makassar. Hal ini ditunjukkan dengan variabel komunikasi internal memiliki nilai lebih tinggi yaitu nilai beta $(\beta)$ sebesar 0,395 dengan nilai $p$-value $<0.002$ dibandingkan dengan variabel disiplin kerja dengan nilai beta $(\beta)$ sebesar 0,373 dan nilai $p$-value 0,04 .

Table 10 Ringkasan model (model summary)

\begin{tabular}{|c|c|c|c|}
\hline Pengukuran & KI & DK & KRJ \\
\hline$R$-squared & & & 0.412 \\
\hline Adj. $R$-squared & & & 0.382 \\
\hline Composite reliab. & 0.805 & 0.969 & 0.941 \\
\hline
\end{tabular}


Issue 1 (October, 2017)

Lanjutan Table 10 Ringkasan model (model summary)

\begin{tabular}{|c|c|c|c|}
\hline Pengukuran & KI & DK & KRJ \\
\hline Cronbach's Alpha & 0.634 & 0.952 & 0.906 \\
\hline Avg. Var. Extrac. & 0,394 & 0,650 & 0,651 \\
\hline
\end{tabular}

Sumber: Data primer (diolah WarphPLS Ver 5.0, 2017)

Berdasarkan tabel diatas besaran pengaruh nilai $\mathrm{R}$-squared pada variabel komunikasi internal dan disiplin kerja terhadap kinerja pegawai adalah 0,412 $(41,2 \%)$ dan sisanya $58,8 \%$ dipengaruhi oleh variabel lainnya yang tidak dianalisis dalam penelitian ini.

\section{a. Pengaruh Komunikasi Internal Terhadap Kinerja Pegawai.}

Berdasarkan hasil penelitian, ditemukan bahwa komunikasi internal memiliki pengaruh terhadap kinerja pegawai. Hasil ini sama dengan teori atau temuan dalam penelitian sebelumnya oleh Udayanto, R. R., Bagia, I. W., Si, M., \& Yulianthini, N. N. (2015). memberikan bukti bahwa komunikasi internal berpengaruh positif dan signifikan terhadap Kinerja karyawan.

Dalam penelitian ini dapat dilihat dari nilai koefisien beta yang menunjukkan bahwa semakin baik komunikasi internal maka semakin tinggi kinerja pegawai yaitu dengan nilai beta $(\beta)$ sebesar 0,395.

Hal ini menunjukkan bahwa variabel komunikasi internal dapat memengaruhi peningkatan kinerja pegawai kearah yang lebih tinggi. Penyebab positif dan signifikannya pengaruh komunikasi internal terhadap kinerja pegawai diakibatkan karena pegawai dalam setiap bekerja terjadi komunikasi internal dalam melaksanakan tugas baik pimpinan yang memberikan tugas dengan menggunakan komunikasi dalam memberikan perintah maupun arahan kepada staf atau bawahan dalam melaksanakan semua tugas untuk dapat diselesaikan dengan cepat dan sesuai dengan standar kerja yang ditetapkan pada SKPD Kesejahteraan Rakyat Kantor Pemerintahan Kota Makassar.

\section{b. Pengaruh Disiplin Kerja Terhadap Kinerja Pegawai.}

Berdasarkan hasil penelitian, ditemukan bahwa disiplin kerja memiliki pengaruh terhadap kinerja pegawai. Hasil ini sama dengan teori atau temuan dalam penelitian sebelumnya oleh Alfian, W. P. (2015) bahwa disiplin kerja berpengaruh positif dan tidak signifikan terhadap Kinerja karyawan.

Dalam penelitian ini dapat dilihat dari nilai koefisien beta yang menunjukkan bahwa disiplin kerja memiliki pengaruh positif dan signifikan terhadap kinerja pegawai yaitu dengan nilai beta $(\beta)$ sebesar 0,373.

Hal ini menunjukkan bahwa variabel disiplin kerja dapat memengaruhi peningkatan kinerja pegawai kearah yang lebih tinggi. Penyebab positif dan signifikannya pengaruh disiplin kerja terhadap kinerja pegawai diakibatkan karena pegawai dalam setiap bekerja

Selalu berlandaskan kedisiplinan yang telah diatur dalam peraturan perundang-undangan kepegawaian sehingga pegawai dituntut untuk bisa disiplin kerja agar semua target kerja dan tujuan dari kantor dapat terlaksana dengan baik sesuai dengan aturan sesuai dengan standar kerja yang ditetapkan pada SKPD Kesejahteraan Rakyat Kantor Pemerintahan Kota Makassar. 


\section{JURNAL ORGANISASI DAN MANAJEMEN}

Issue 1 (October, 2017)

\section{c. Pengaruh Komunikasi Internal Dominan Dibandingkan Dengan Disiplin Kerja Terhadap Kinerja Pegawai.}

Berdasarkan hasil penelitian, ditemukan bahwa pengaruh komunikasi internal lebih dominan dibandingkan pengaruh disiplin kerja terhadap kinerja pegawai. Hasil tersebut dalam penelitian ini dapat dilihat dari nilai koefisien beta yang ditunjukkan komunikasi internal lebih tinggi yaitu dengan nilai beta $(\beta)$ sebesar 0,395 dan nilai koefisien beta yang ditunjukkan oleh disiplin kerja yaitu dengan nilai 0,373 .

Hal ini menunjukkan bahwa variabel komunikasi internal dapat memengaruhi peningkatan kinerja pegawai kearah yang lebih tinggi dibandingkan variabel disiplin kerja. Penyebab positif dan signifikannya dominan pengaruh komunikasi internal terhadap kinerja pegawai diakibatkan karena pegawai dalam bekerja, pegawai dalam setiap bekerja terjadi komunikasi internal dalam melaksanakan tugas baik pimpinan yang memberikan tugas dengan menggunakan komunikasi dalam memberikan perintah maupun arahan kepada staf atau bawahan dalam melaksanakan semua tugas untuk dapat diselesaikan dengan cepat dan sesuai dengan standar kerja yang ditetapkan pada SKPD Kesejahteraan Rakyat Kantor Pemerintahan Kota Makassar.

Kondisi tersebut didukung dengan menjaga rasa saling membantu dan menghargai terhadap sesama rekan kerja dan menunjukkan loyalitas kerja yang tinggi terhadap instansi dan rekan kerja saya sehingga berdampak nyata terhadap tuntutan agar pekerjaan terselesaikan dengan tepat waktu sehingga tidak menimbulkan permasalahan yang menghambat pegawai dalam menyelesaikan pekerjaannya pada SKPD Kesejahteraan Rakyat Kantor Pemerintahan Kota Makassar.

\section{Kesimpulan}

Komunikasi internal berpengaruh positif dan signifikan terhadap kinerja pegawai. Berdasarkan hasil penelitian diketahui bahwa hasil menunjukkan bahwa $\beta=0,395$ dan $p$-value sebesar $<0,002(\leq 0,05)$. Penelitian ini menggunakan tingkat signifikansi kesalahan sebesar $5 \%$ atau 0,05 , sehingga dengan p-value sebesar $<0,002(\leq 0,05)$ menunjukkan bahwa komunikasi internal berpengaruh terhadap kinerja pegawai pada SKPD Kesejahteraan Rakyat Kantor Pemerintahan Kota Makassar. Disiplin kerja berpengaruh positif dan tidak signifikan terhadap kinerja pegawai. Berdasarkan hasil penelitian diketahui bahwa hasil menunjukkan bahwa $\beta=0,373$ dan $p$-value sebesar $<0,004(\geq 0,05)$. Penelitian ini menggunakan tingkat signifikansi kesalahan sebesar $5 \%$ atau 0,05 , sehingga dengan p-value sebesar $<0,004 \quad(\geq 0,05)$ menunjukkan bahwa disiplin kerja berpengaruh terhadap kinerja pegawai pada SKPD Kesejahteraan Rakyat Kantor Pemerintahan Kota Makassar.Komunikasi internal dominan berpengaruh dibandingkan disiplin kerja terhadap kinerja pegawai. Berdasarkan hasil penelitian diketahui bahwa hasil komunikasi internal menunjukkan $\beta=0,395$ dan $p$-value sebesar $<0,002(\leq 0,05)$ dan hasil disiplin kerja menunjukkan menunjukkan $\beta=0,373$ dan $p$-value sebesar $<0,004(\geq 0,05)$. Penelitian ini menggunakan tingkat signifikansi kesalahan sebesar $5 \%$ atau 0,05 , sehingga menunjukkan bahwa komunikasi internal dominan berpengaruh terhadap kinerja pegawai pada SKPD Kesejahteraan Rakyat Kantor Pemerintahan Kota Makassar.

Disarankan kepada peneliti lanjutan agar objek penelitian sebaiknya diperluas, sehingga hasil yang diperoleh lebih maksimal dan lebih dapat memberikan gambaran yang lebih jelas mengenai pengaruh komunikasi internal dan disiplin kerja terhadap kinerja pegawai secara menyeluruh. Dalam hal waktu, 


\section{JURNAL ORGANISASI DAN MANAJEMEN}

Issue 1 (October, 2017)

hendaklah peneliti selanjutnya dapat memiliki waktu yang cukup untuk melakukan penelitian sehingga bisa mencapai hasil yang maksimal. Peneliti selanjutnya diharapkan dapat menambah beberapa variabel independen lainnya agar variabel tersebut mampu menjelaskan variabel dependen lebih besar dari penelitian sebelumnya sehingga mendapatkan hasil yang lebih akurat.

Disarankan kepada pada Kantor Walikota Bagian SKPD Kesejahteraan Rakyat Kantor Pemerintahan Kota Makassar untuk lebih meningkatkan pengimplementasian komunikasi internal dan disiplin kerja dalam menunjang kinerja pegawai.

\section{DAFTAR PUSTAKA}

Agung karismadiyanto. (2014). Analisis Pengaruh Motivasi Kerja, Disiplin Kerja Dan Komunikasi Terhadap Kinerja Karyawan. Jurnal. Jember : Fakultas Ekonomi. Universitas Muhammadiyah

Alfian, W. P. (2015). Pengaruh Kepemimpinan, Komunikasi, Motivasi Dan Disiplin Kerja Terhadap Kinerja Karyawan Ekspedisi Trans Jaya Semarang. Skripsi, Fakultas Ekonomi \& Bisnis.

Amin. (2016). Peranan Faktor Karakteristik Individu dan Faktor Organisasi terhadap Kinerja Pegawai Dinas Pertanian Tanaman Pangan Provinsi Bali

Arifin. M dan Barnawi. (2012). Manajemen Sarana dan Prasarana Sekolah. Jakarta : Ar-. Ruzz Media.

Augusty, Ferdinand. (2006). Metode Penelitian Manajemen: Pedoman Penelitian untuk skripsi, Tesis dan Disertai Ilmu Manajemen. Semarang : Universitas Diponegoro.

Bambang Prasetyo, Lina Miftahul Jannah. (2005). Metode Penelitian. Kuantitatif : Teori dan Aplikasi. Jakarta : Penerbit PT. Raja Grafindo.

Dessler, Gary. (2010). Manajemen Sumber Daya Manusia. Jakarta : PT. Indeks.

Dwi Agung Nugroho Arianto. (2013). Pengaruh Kedisiplinan, Lingkungan Kerja dan Budaya Kerja Terhadap Kinerja Tenaga Pengajar. Jurnal. Jepara : Universitas Islam Nahdlatul Ulama.

Effendy, Onong Uchjana. (2007). Ilmu Komunikasi (teori dan Praktek). Bandung : PT. Remaja Rosdakarya.

Hery. (2009). Akuntansi Keuangan Menengah. Jakarta: Bumi Aksara.

Miftah Thoha. (2004). Perilaku Organisasi, Konsep Dasar dan Aplikasinya. Jakarta : Raja Grafindo Persada.

Mudrajat Kuncoro, (2009). Manajemen Personalia dan Sumber Daya. Edisi 2. Yogyakarta : BPFE.

Nurjaman, Kadar \& Khaerul Umam. (2012). Komunikasi \& Public Relation. Bandung : Pustaka Setia.

Pace, R. Wayne dan Don F. Faules. (2013). Komunikasi Organisasi: Strategi Meningkatkan Kinerja Perusahaan, Terj. Deddy Mulyana. Bandung: PT Remaja RosdaKarya

Rahmad Restu Udayanto, I Wayan Bagia, dan Ni Nyoman Yulianthini. (2015). Pengaruh Komunikasi Internal dan Disiplin Kerja Terhadap Kinerja Karyawan Pada PT. Coca-Cola. Jurnal Bisma Universitas Pendidikan Ganesha. Singaraja : Universitas Pendidikan Ganesha. 


\section{JURNAL ORGANISASI DAN MANAJEMEN}

Issue 1 (October, 2017)

Rezza Efendy \& Herman Sjahruddin. (2016). Praktik Motivasi Kerja dan Konsekuensinya Pada Kinerja Aparatur Sipil Negara. Makassar : ELibrary STIE YPBUP Bongaya.

Rivai, Veitzal \& Ella Jauvani Sagala. (2013). Manajemen Sumber Daya Manusia untuk Perusahaan. Jakarta : PT Raja Grafindo Persada

Rizki Wicaksono Suwardi. (2015). Pengaruh Komunikasi, Kompensasi, dan Komitmen Pada Kinerja Karyawan di PT. Tirta Investama DC Ciputat. Jurnal. Universitas Gunadarma.

Samsudin, Sadili. (2009). Manajemen Sumber Daya Manusia. Bandung : CV. Pustaka Setia.

Sholihin, Mahfud dan Ratmono, Dwi. (2013). Analisis SEM-PLS dengan WrapPLS 3.0 Untuk Hubungan Nonlinear dalam Penelitian Sosial dan Bisnis. Yogyakarta : Penerbit Andi.

Sriwidodo, Untung dan Agus Budhi Haryanto. (2010). Pengaruh Komunikasi Dan Kesejahteraan Terhadap Kinerja Pegawai Dinas Pendidikan Kabupaten Sukoharjo . Jurnal Manajemen Sumber daya Manusia Vol. 4 No. 148 Juni 2010: $47-57$

Sugiyono, (2013). Metode Penelitian Bisnis (Pendekatan Kuantitatif, Kualitatif, dan R\&D. Cetakan Ke-17 Bandung : Alfabeta

Sumaki, W. J., Taroreh, R. N., \& Soepeno, D. (2015). Pengaruh Disiplin Kerja, Budaya Organisasi, Dan Komunikasi Terhadap Kinerja Karyawan PT. PLN (PERSERO) Wilayah Suluttenggo Manado. Jurnal Riset Ekonomi, Manajemen, Bisnis Dan Akuntansi

Tim Penyusun. (2016). Pedoman Penulisan Skripsi. Makassar : Sekolah Tinggi IImu Ekonomi Makassar (STIEM) Bongaya.

Undang-Undang Nomor 5 Tahun 2014 tentang Aparatur Sipil Negara.

Wicaksono, A. K., \& Soesatyo, Y. (2015). Hubungan Komunikasi Internal Organisasi Dengan Keefektifan Kerja Guru Dan Karyawan Di Sekolah Menengah Kejuruan Negeri (SMKN) 2 TRENGGALEK. Jurnal Administrasi Perkantoran (JPAP). Surabaya : Fakultas Ekonomi Universitas Negeri Surabaya.

Yamin, Sofyan dan Heri Kurniawan, (2009). SPSS COMPLETE Teknik Analisis Statistik Terlengkap dengan Software SPSS. Jakarta : Salemba Infotek

Yuanita Widyanti Sofiana Sari. (2014). Pengaruh Komunikasi Internal, Reward dan Punisment Terhadap Motivasi Kerja Karyawan di BPR Nur Semesta Indah Kencong Kabupaten Jember. Jurnal. Jember : Fakultas Ekonomi. Universitas Muhammadiyah. 